\title{
De direito social a dispositivo de saúde: o trabalho na legislação de saúde vigente
}

\author{
From social right to health device: labor in prevailing health law \\ De derecho social a dispositivo de salud: el trabajo en la legislación de salud vigente \\ Eneida Santiago ${ }^{I}$ \\ Universidade Estadual de Londrina \\ Silvio Yasui ${ }^{2}$ \\ Universidade Estadual Paulista- Unesp/Assis
}

\begin{abstract}
Resumo
A partir das contribuições teóricas de Michel Foucault e da leitura crítica da Declaração Universal dos Direitos Humanos e da Constituição Brasileira de 1988, este artigo mapeia a constituição do Trabalho como dimensão que passa de direito social a dispositivo de saúde. Em nossas análises verificamos que o trabalho como direito social e dispositivo de saúde tem seu protagonismo subjetivo, social e econômico contemplado pelos documentos. No entanto, ao definir e orientar modos de ser dos sujeitos que trabalham os discursos proferidos enquadram e controlam dificultando a abertura dos trabalhadores para os movimentos de criação e ampliação da vida e do trabalho em sua positividade de experimentações. Concluímos destacando que não basta reconhecer o trabalho como direito social, indicar seu protagonismo como estratégia de saúde ou direcionar esforços políticos sem problematizar "que tipo de trabalho" pode ser auxiliador na construção mais criativa do próprio Trabalho e da Saúde.

Palavras-chave: Saúde coletiva; Saúde pública; Psicologia do trabalho; Políticas públicas.
\end{abstract}

\begin{abstract}
Starting from the theoretical contributions of Michel Foucault and from a critical appraisal of the Declaration of Universal Human Rights and the 1988 Brazilian Constitution, this article maps the constitution of labor as a dimension that goes from social right to health device. In our analysis we find that labor as a social right and health device has a subjective protagonism and has social and economic aspects contemplated by documents. However in defining and orienting ways of being of individuals that work delivered speeches that fall in and control, hindering the openness of workers for movements of creation expansion of life and work in its positivity of experimentations. We conclude that is not enough to recognize labor as a social right, indicate its role as a health strategy or direct political efforts without problematizing not "what kind of work" can be supportive in a more creative construction of its own work and health.

Key-words: Collective health; Public health; Occupational psychology; Public policy.
\end{abstract}

\section{Resumen}

A partir de los aportes teóricos de Michel Foucault y la lectura crítica de la Declaración Universal de los Derechos Humanos y de la Constitución Brasileña de 1988, este artículo traza la constitución del Trabajo como una dimensión que pasa de ser un derecho social a ser un dispositivo de salud. En nuestro análisis encontramos que el trabajo como derecho social y como dispositivo de salud social tiene un protagonismo subjetivo, social y económico que es contemplado por los documentos. Sin embargo, al definir y orientar formas de ser de las personas que trabajan, los discursos encontrados clasifican y controlan, haciendo más difícil la apertura de los trabajadores hacia movimientos de creación y expansión de la vida y del trabajo en sus experimentaciones, que pueden ser muy positivas. Llegamos a la conclusión de que no es suficiente reconocer el trabajo como un derecho social, indicar su protagonismo como estrategia de salud o dirigir esfuerzos políticos hacia una dirección sin cuestionar "qué tipo de trabajo " puede contribuir con la construcción más creativa del propio Trabajo y de la Salud.

Palabras-clave: Salud colectiva; Salud pública; Psicología del trabajo; Políticas públicas.

\section{DE DIREITO SOCIAL A DISPOSITIVO DE SAÚDE: UMA ANÁLISE DO TRABALHO NA LEGISLAÇÃO DE SAÚDE VIGENTE}

O olhar atento para a relação entre Trabalho e Saúde permite a identificação de uma íntima e histórica proximidade que tem sido intensificada

Endereço 1: Rodovia Celso Garcia Cid, Pr 445 - Km 380, Campus Universitário Cx. Postal 10.011, Cep.: 86.057-970, Londrina - PR Endereço 2: Av. Dom Antonio, 2100 - Parque Universitário Cep.: 19.806-900, Assis - SP contemporaneamente quando preconiza-se a conexão do trabalho com políticas, eixos de ações e serviços de saúde para tentar a integralidade da vida (Santiago \& Yasui, 2011). Pensar o Trabalho (suas nuances, dimensões e contrastes) é claramente importante, mas notamos que pouco, reflete-se sobre sua crescente presença e composição com outras áreas e campos de saberes, como nas ações e políticas de intersetorialidade e integralidade. Inversamente, a orientação para essa composição é cada vez maior (Brasil, 2009; Conselho Nacional de Saúde, 2010).

A partir disso, esclarecemos que neste artigo 
discutimos a constituição do Trabalho como direito social e problematizamos sua emergência como dispositivo de cuidado na Legislação de Saúde vigente. Para mapear e refletir sobre esse processo, analisamos a Declaração Universal dos Direitos Humanos (DUDH) e a Constituição Federal Brasileira de 1988. A escolha por esses documentos faz consonância com nosso objetivo de contemplar escritos que versam sobre os direitos sociais básicos e são reconhecidos e aceitos social e juridicamente na atualidade, além de explanarem sobre o planejamento e a gestão da vida em sociedade em que políticas e práticas de saúde, sociais e econômicas são articuladas. Tais publicações publicizam atos e informações proferidas pelo poder público apresentando as políticas de Estado que estabelecem diretrizes e orientam ações. Metodologicamente, a partir das ferramentas analíticas genealógicas de Michel Foucault, operamos o mapeamento e análise das composições de forças da constituição Trabalho-Saúde, refletindo sobre o estabelecimento dessa complexidade e dos possíveis limites de tal ligação.

\section{Contribuições Foucaultianas}

Nos anos 70, Foucault introduz a Genealogia do Saber como um modo de problematizar as práticas sociais a partir de questionamentos do por que do "aparecimento dos saberes a partir de condições de possibilidade externas aos próprios saberes" (Foucault, 1986, p. X). A genealogia, através da dispersão de determinismos históricos e naturalizados, demonstra que a investigação dos vários sentidos e configurações dos discursos é um instrumento capaz de lançar luz aos processos de produção desses mesmos discursos como divulgadores de saberes, sendo que para Foucault Saber, Poder e Subjetivação são indissociáveis. Ao genealogista caberia a pesquisa que "agita o que se percebia imóvel, ela fragmenta o que se pensava unido; ela mostra a heterogeneidade do que se imaginava em conformidade consigo mesmo." (Foucault, 1986, p. 21). Assim, não há discurso que não possa e deva ser desenraizado de sobreposições de falsas certezas que enquanto redes de discursos-acontecimentos imbricam-se em práticas de poder, formando dispositivos. O dispositivo é uma formação que em determinado momento histórico é estabelecida com uma função estratégica dominante: a de responder a uma demanda ou urgência, envolvendo e contemplando saber, poder e processos de subjetivação em um emaranhado heterogêneo de discursos, arquiteturas, instituições, proposições e normatizações legais e morais (Foucault, 1986).

Os discursos atravessados por relações de poder, têm efeitos de verdades e suscitam modos de ser, pensar, sentir: viver. Tornam-se um interlaçamento de forças que é dinâmico e relacional, sustentando dispositivos institucionais e legais que pautam-se em verdades que são repetidamente enunciadas, reforçando a si mesmas, compondo documentos vários (como arquivos, manuais, legislações) que são espaços de registros de discursos-acontecimentos configurados de saberes-poderes que objetivam pessoas e grupos sociais. É todo um campo documental que além de produzirem, também fazem circular saberes que têm efeitos conjugados de forças. O trabalho do genealogista seria dedicar-se aos documentos que narram e constroem o desenrolar da vida ao capturarem e registrarem peças, passagens e ocorrências para serem manuseadas por olhares inquietantes.

Assim, neste artigo ao analisarmos determinadas legislações, podemos nos interrogarmos que táticas foram agenciadas para a produção de discursos e documentos sobre a relação entre Trabalho e Saúde. Refletimos quanto a preconização de posturas e práticas, e sobre os dizeres nos papéis que possam denunciar olhares evolucionistas e normatizantes, conceituações simplificadas e deterministas, que promovem cortes entre as coisas e as palavras que as nomeiam. Problematizamos verdades e relações de saber-poder que produzem subjetividades, realidades e outros saberes, buscando evidenciar formas do exercício de poder para além do Estado e seus braços, visto que o poder não está localizado exclusivamente em seus aparelhos, constituindo uma rede em que forças de resistência e dominação movimentam-se continuamente, o poder deve ser pensado em termos de relações que produzem atravessamentos e tensões dos quais podemos nos aproximar pela análise de seus efeitos provisórios, e não pela busca de suas origens (Foucault, 1986).

Neste contexto teórico, apresentamos alguns operadores metodológicos foucaultianos que orientam as análises aqui realizadas. Esses operadores são os conceitos de tecnologia disciplinar (enquanto relações de poder exercidas no corpo dos indivíduos com fins de adestramento e docilidade); sociedade disciplinar (como emergência da administração do corpo no campo político); biopolítica e normalização (com as ações disciplinares, produzem normas comparativos dos indivíduos frente há medidas de referência) (Foucault, 1986; 2003).

\section{Trabalho e Saúde: Discussões Necessárias}

O "direito ao trabalho" e o "direito à saúde" compõem os chamados direitos sociais básicos, ou seja, as condições materiais imprescindíveis para que a vida aconteça de forma a ser considerada digna. Dessa forma, cartografar a relação e a composição desses direitos é a oportunidade de acompanharmos e problematizarmos as ausências e presenças na arquitetura organizativa desta dimensão tão complexa e tão essencial: a experiência trabalho, como direito social e como dispositivo de saúde. Em uma necessária clareza de que o Trabalho é ao mesmo tempo um 
reflexo da complexidade de nossa existência subjetiva e singular, sendo igualmente uma dimensão de nossa vida societária.

A Declaração Universal dos Direitos Humanos (DUDH): o trabalho como um direito

$\mathrm{Na}$ DUDH (1948) há o reconhecimento internacional de diversos direitos do homem, como o direito à liberdade, à família, ao trabalho, à saúde, à cidadania, entre outros. Pela primeira vez alguns aspectos da vida subjetiva, social, econômica e política são contemplados como componente existencial. $\mathrm{O}$ Trabalho é um exemplo disso. É aqui que ele, pela primeira vez, é colocado como imprescindível à nossa humanidade. E essa primazia, nos anos 40, traduziuse pela sua composição como direito humano.

A DUDH foi aprovada definitivamente em 1948 em Assembleia Geral da Organização das Nações Unidas (ONU), sendo um documento resultado de um processo de reflexão e esforços iniciado em 1945, para que as violações e opressões contra as pessoas em suas prerrogativas humanas e liberdades individuais ocorridas na Segunda Guerra Mundial, então recentemente encerrada, não mais se repetissem. Anterior a esse período outros documentos já tinham sido elaborados como forma de reação as injustiças e tratamentos desumanos, como a Declaração dos Direitos do Homem e do Cidadão (redigida pós Revolução Francesa). Para a constituição da base do que viria a ser a DUDH, os esforços tornaramse declaradamente internacionais e não mais de comunidades isoladas. Apesar disso, apenas membros de oito países envolveram-se com a confecção do primeiro esboço. Posteriormente, representantes de 50 países participaram da redação da versão final.

Desde sua adoção a DUDH foi traduzida para centenas de idiomas e inspirou a constituição de Tratados, Pactos e Protocolos, expandindo o corpo do direito internacional dos direitos humanos. Desde a aprovação da Declaração, a ONU assumiu uma posição de monitoramento de violações de seus preceitos, chegando a dispender auxílio financeiro e material para a manutenção dos direitos humanos como forma de permanência da paz e da segurança internacional (ONU Brasil, 2013).

Em termos jurídicos, originalmente a DUDH foi tecnicamente interpretada como uma recomendação, não tendo força legal. Pelo excesso de formalismo, essa compreensão foi abandonada. Nas últimas décadas quanto à vigência dos direitos humanos, há o entendimento amplamente defendido de sua força vinculante universal, ou seja, como instrumento de justiça coletivamente aceito, mas não contemplado pela letra jurídica. Em contrapartida, a pauta dos diretos humanos tem estado cada vez mais presente nas políticas de Estado dos variados países. Quanto as suas proposições, a DUDH é avaliada pela ONU como "um documento marco na história dos direitos humanos" (ONU Brasil, 2013, p. 02). Ao ser proclamada "como uma norma comum a ser alcançada por todos os povos e nações, ela estabelece, pela primeira vez, a proteção universal dos direitos humanos" (ONU Brasil, 2013, p. 02). O Ministério da Justiça Brasileiro, em uma análise sobre a DUDH, afirma ser este um guia para garantir os direitos essenciais de todas as pessoas, destacando seus aspectos políticos e civis, e suas dimensões econômicas, sociais e culturais (Ministério da Justiça, 2013).

Com a amplitude necessária para acolher diferenças e particularidades, os direitos humanos como direitos básicos do homem, colocam lado a lado questões tanto objetivas quanto subjetivas, tanto biológicas quanto econômicas e sociais, como estar vivo e estar livre, ou estar livre e estar saudável. Questões que são fundamentais, mas não bastam por si.

Dissertando sobre a questão do trabalho como direito humano básico que atrela aspectos sociais, econômicas e laborais em seu $23^{\circ}$. artigo a DUDH destaca como condições deste direito a livre escolha e as condições justas e protegidas de seu exercício do trabalho.

A partir destes pontos no artigo citado, e da leitura atenta de todo o documento, podemos afirmar que na DUDH a concepção do direito ao trabalho organiza-se em três frentes discursivas, que são: 1 . do trabalho diretamente ligado a categoria "emprego" e a manutenção deste; 2 . do trabalho provedor de uma remuneração financeira, e esta como imperativa da vida material e imaterial; 3 . da possibilidade do estabelecimento de enfrentamentos às desmazelas produzidas pelo trabalho pela filiação sindical.

Há na Declaração um esforço na construção de uma justiça corretiva com a produção de equidade, o que é uma dualidade. A equidade, enquanto disposição em reconhecer o direito de cada um pressupõe a negociação e o estabelecimento de normas comuns que implicam um balanço, por parte dos indivíduos, entre ganhos e perdas da escolha de obedecer uma regra. Desta forma, os direitos trazidos pela Declaração são normas apresentadas como condição para adentrar nossa humanidade em diversos aspectos, por isso ser um "direito humano".

Com relação ao trabalho, afirmamos que a DUDH produz uma mediação das relações entre trabalhador, trabalho e capital. Apesar da tríade, e de apresentar seu conteúdo como um "objetivo de que cada indivíduo e cada órgão da sociedade, tendo sempre em mente esta Declaração, se esforce, através do ensino e da educação, por promover o respeito a esses direitos e liberdades" (DUDH, 1948, p. 02), há em todo o documento um direcionamento discursivo ao indivíduo (trabalhador) como principal agente a alcançar o normatizado.

Mesmo compondo com 10 outros direitos sociais básicos, o trabalho na DUDH fica solitário, já que não é articulado com nenhuma dimensão subjetiva 
e interdisciplinar, restando a ele a objetividade. E diante da norma objetiva a vida cheia de saltos exigirá malabarismos. Ewald (1993), afirma como que atualmente o balanço a ser feita para compartilhar, ou não, as normas socialmente colocadas como direitos e deveres deixam de ser permanentes, tornandose um movimento de balanços a serem feitos e refeitos, renovados perpetuamente e muitas vezes flexibilizados. Assim, segundo o autor, a justiça social a partir de suas medidas comuns de garantia e acesso a direitos, torna-se mediada pelas normas sociais as quais pactuamos.

Como guia que pretende ser a sustentação da luta pelos direitos e liberdades das pessoas, podemos afirmar ser a DUDH um documento que aponta um direito normalizado e normalizador ao oferecer um modelo organizador que disciplina o olhar para uma determinada sequência de "prioridades" do homem que trabalha (emprego-remuneração-associação sindical) e assim profere, resumida e simplificadamente, serem estas as normas, a "base" do exercício da cidadania e dos direitos humanos relacionados ao trabalho. Lembramos como que para Foucault a norma que igualiza é a mesma que diferencia os indivíduos ao fornecer medidas comparativas e classificatórias de equivalência. A norma é uma medida comum que permite que cada indivíduo pense sua identidade, e por consequência, seu lugar no jogo social. "A norma convida cada indivíduo a reconhecer-se diferente dos outros, encerra-o no seu caso, na sua individualidade, na sua irredutível particularidade. Precisamente, o normativo afirma tanto mais a igualdade de cada um perante todos, quanto infinitiza as diferenças" (Ewald, 1993, p. 109).

Desta forma, as normas colocadas pela DUDH no âmbito do trabalho, marcam como identidade mestre o "trabalhador formal", e como identidades satélites dessa primeira, possibilidades polarizadas: o "trabalhador/não trabalhador; trabalho formal/ informal; condições justas/injustas de trabalho; dentre outras. Lembrando que nossa identidade é um indicativo da vida que construímos. Como tal, ao disponibilizar um cardápio de identidades possíveis a Declaração estabelece fronteiras nas possibilidades de modos de vida a serem constituídos, priorizando destinos fundamentados em definições próprias de segurança, liberdade e felicidade.

Compreendemos que o documento agora discutido traga o privilégio do "emprego", e não do "trabalho" ou "ocupação". Isso porque lembremos que enquanto escritura jurídica referida a princípios de racionalidade, a DUDH e suas recomendações estão localizadas em um contexto sócio-políticoeconômico em que as discussões sobre as diferenças entre os termos destacados (emprego/trabalho) e suas utilizações, são recentes. Justifica-se até certa medida o uso do termo "emprego", já que poderíamos fazer a seguinte questão: porque seu discurso não foi alterado a partir das discussões recentes realizadas em espaços acadêmicos e políticos?

Como importante perito de normas o Estado ainda é fortemente direcionado pela questão do emprego, e não do trabalho. Apesar de não ser uma máquina alheia à sociedade, o Estado é a materialização das contradições e tensões desta. Assim, apesar de produzir esforços em ações geradoras e direcionadas ao trabalho, o Estado ainda reflete uma questão social maior: a da dificuldade de construir modos de vida pautados pelo trabalho e pela ocupação, de forma menos mercadológica e competitiva do que o emprego, além de mais includentes.

É categórica a inovação que a DUDH promove em variados aspectos, como abrindo espaço legal, político e social para discussões das nuances mais amplas e diversas da existência humana, ou ao tentar promover uma ruptura com o cerceamento do acesso aos direitos sociais a grupos específicos. Mas lembramos de que a DUDH é um conjunto de enunciados situados em uma sociedade específica, ou seja, remete às questões e concepções datadas e de um contexto específico, não devendo ser compreendida como um documento imparcial, mas sim fruto de interesses, alianças e projetos políticos vários.

Fonseca e Araújo (2011) apontam para a influência da DUDH no ordenamento da Constituição Brasileira promulgada em 1988, em que os direitos humanos básicos ocupam uma posição de supremacia no arranjo jurídico. É no documento da Constituição que agora nos aprofundamos.

\section{A Constituição Brasileira: trabalho e saúde como direitos articulados}

Na Constituição de 1988 os direitos humanos são princípios de garantias fundamentais. Em comparativo às Constituições anteriores, destaca-se a inclusão dos direitos transindividuais para além da divisão em classes, a ampliação dos direitos sociais para além da saúde, da educação e da previdência.

No âmbito do Trabalho, o documento de 1988 o reconhece como um direito social (assim como a educação, a saúde, dentre outros) pautado em um Estado democrático de direito que tem como alicerce o que denomina de valor social do trabalho (Brasil, 1988). Por valor social compreendem-se os direitos que possibilitam o exercício profissional com dignidade, remuneração justa e condições mínimas para a sobrevivência. Sendo que "A ordem econômica, fundada na valorização do trabalho humano e na livre iniciativa, tem por fim assegurar a todos existência digna, conforme os ditames da justiça social" (BRASIL, 1988, p. 73, art.170). Além disso, busca-se a "redução das desigualdades regionais e sociais; (...) (e o) pleno emprego" (Brasil, 1988, p. 73, art. 170).

Dissertando sobre direitos e condições diversas que envolvem o trabalho (muitos sendo discutidos pela primeira vez de maneira mais demorada), a 
Constituição, assim como a DUDH, coloca sob destaque a remuneração (na forma de salário, seguro-desemprego ou fundo de garantia em caso de demissão sem justa causa) como meio de obtenção e manutenção de uma existência mais justa. Há no documento em questão, a obrigação do Estado em garantir que o direito à remuneração digna seja contemplado. Quando não, o mesmo Estado deve disponibilizar meios de proteção social (Brasil, 1988). As estratégias que envolveriam a busca por esse "dever" do Estado são esclarecidos no artigo que contempla a saúde:

A saúde é direito de todos e dever do Estado, garantido mediante políticas sociais e econômicas que visem à redução do risco de doença e de outros agravos e ao acesso universal igualitário às ações e serviços para sua promoção, proteção e recuperação (Brasil, 1988, p. 80, art. 196.).

A proposição da proteção não fica restrita ao âmbito da saúde, do trabalho ou da remuneração, ela estende-se às outras composições da vida coletiva e social, como a família, a infância, a maternidade, dentre outros. A assistência como meio de amparo, promoção e integração social torna-se garantida por lei sendo concretizada pela concessão mensal de um benefício financeiro.

A perspectiva ampliada da vida que os artigos da Constituição expõem, coloca em pauta os esforços que o Estado precisaria empreender para que a proteção social almejada ocorresse. Destacam-se as distintas posições que esse mesmo Estado impõe-se diante de grupos sociais a serem contemplados pelas determinações: protegem-se alguns, amparam-se outros. Sendo fundamental, mas ausente pela nossa percepção, a clareza dos parâmetros da composição de cada um desses grupos, orientações para a implementação de práticas concretas que impeçam esses grupos de necessitarem de atenção protecionista específica.A partir das contribuições foucaultianas (Foucault, 2005), afirmamos que a designação "proteção social" esconde uma tarefa preventivista. As virtualidades das ações (do que pode vir a ser e ocorrer) seriam capturadas, dimensionadas e traduzidas em estratégias de biopolítica e governamentabilidade enquanto avanço das tecnologias de poder: do governo do corpo (da sociedade de disciplina), para o governo da vida, das populações (na sociedade de controle), como já sinalizado por Deleuze (2010).

Não somente um foco, mas uma rede de proteção conduzida pelo Estado e composta de variados segmentos, começa a ser estabelecida no Brasil a partir da Constituição de 1988, promovendo políticas

1- Na atualidade, um exemplo dessa questão é o reconhecimento dos direitos civis de minorias que cada vez mais colocam-se em oposição à ceder aos imperativos de identidades normativas, exaltando à liberdade e respeito a diversidade. A história da luta do movimento LGBT (Lésbicas, Gays, Bissexuais, Travestis e Transexuais) mostra a constituição dessa reivindicação. e práticas de governo dos indivíduos e dos coletivos cada vez mais dilatados. Essa rede ganhará em requintes e estenderá seus braços a grupos cada vez mais específicos, na minúcia que é "do detalhe do detalhe" . Em todas essas ramificações da norma e dos processos de normatização, a noção de risco tornase inerente para o alcance dos objetivos propostos, necessitando ser problematizada. Mas, porque falar dos riscos?

Para Spink (2010, p. 299), “a mensuração do risco tornou-se uma ferramenta útil para o governo de populações". A autora aponta como que a análise da categoria risco tornou-se um forte indicativo da passagem de uma sociedade disciplinar para (referendando-se em Ulrich Beck) uma sociedade de risco. Diferentemente da denominação de Deleuze (2010), ela sugere um deslocamento dos processos de gestão da vida para a gestão do risco, esclarecendo que contemporaneamente o governo é lançado em direção ao risco que permearia a vida e as populações. Mapear e analisar o risco torna-se uma forma de relacionarse com o futuro, de objetivá-lo. Por isso, os cálculos de probabilidades ganham relevo no capitalismo moderno, bem como áreas como a Medicina Social, a Demografia e a Economia Política, enquanto ciências de Estado que auxiliariam na mensuração do imprevisível (Spink, 2010; Luz, 2001), em que risco tem conotações negativadas, calcadas na ideia de perigo.

Utilizando as reflexões de Foucault, Spink (2010) sinaliza que na sociedade disciplinar em uma gestão da vida, em um primeiro momento a partir do sec. XVII, o foco era o corpo-máquina em toda sua otimização moldada por dispositivos disciplinares. Em um segundo momento, em meados do sec. XVIII, o corpo-espécie ganha destaque, bem como as técnicas de governabilidade, biopoderes e biopolíticas constituem-se (sendo para a autora estratégias essenciais para a gestão do risco por almejarem a segurança). Os dispositivos disciplinares não deixariam de ser utilizados como estratégia de governo, mas a contemporaneidade teria trazido mudanças na natureza do risco, ao mesmo tempo em que o teria colocado como conceito central:

O risco é, talvez, inerente à vida: viver, diz o ditado, é um risco. Entretanto, o sentido que lhe é dado está implicitamente vinculado ao contexto histórico em que os vários riscos se concretizam. É de especial interesse a progressiva expansão das fronteiras espaciais e temporais que fazem com que os riscos possam ser percebidos para além das subjetividades individuais, para além das fronteiras territoriais e até mesmo para além das fronteiras planetárias. São essas transformações, intrinsecamente associadas aos avanços das tecnologias de comunicação, que possibilitam afirmar que estamos vivendo uma transição que nos leva do risco como fenômeno focal da sociedade moderna à sociedade de risco. (Spink et al., 2002, p. 151). 
A sociedade contemporânea, como uma sociedade de risco, dedica-se a construir e administrar complexos mecanismos de gestão do imponderável, mas ao mesmo tempo são cada vez mais presentes os riscos manufaturados. A autora aponta quatro aspectos presentes na gestão das populações quanto a lidar com as probabilidades de ocorrências: a emergência de sistemas transdisciplinares; a gestão da informação (de sua origem e circulação); a ressignificação da ética (de prescrita para dialogada) e a configuração de movimentos sociais de resistência globalizados que utilizam a internet como território de trocas, substituindo o tempo-espaço local (Spink, 2010).

A construção dos possíveis sentidos existenciais na contemporânea sociedade do risco coloca a autorregularão do estilo de vida como ferramenta primordial, bem como o monitoramento de indicativos de qualidade. É a eclosão de outro sentido no repertório interpretativo do risco, agora positivado: o risco-aventura, enquanto "ousadia passível de levar a descobertas" (Spink, 2010, p. 1282). A positividade defendida pela autora, e tão presente na contemporaneidade, seria expressa pela aventura, enquanto possibilidade de encontrar o novo.

Em trechos da Constituição a mensuração do risco pode ser identificada, como quando coloca não só a previsão da existência de pessoas que não consigam prover sua subsistência (deficientes e idosos), mas na igual identificação da impossibilidade da família em assumir esse lugar de forma substituível. Estando também já estabelecida a estratégia governamental para ampará-los: a garantia de um salário mínimo de benefício estatal. O risco é avaliado e previsto em uma dupla negatividade: da falha do sujeito e da família.

$\mathrm{O}$ risco negativado evidencia a impossibilidade, enquanto que o risco-aventura colocaria a positividade do espaço de experimentação e criação-recriação da situação denominada risco (da questão foco). $\mathrm{O}$ risco negativado, com o objetivo de proteção, prevê e tenta evitar o próprio risco.

Afirmamos que os documentos até aqui analisados, quanto à configuração do direito ao trabalho, o direito a saúde e a relação entre ambos, proferem uma discursividade calcada no risco negativo. Isso porque bradam sobre condições justas e favoráveis de trabalho, mas pouco versam sobre o contexto em que estão, que é adverso. Como ilustração dessa adversidade, apresentamos dados noticiados pela Federação das Indústrias do Estado de São Paulo (FIESP) em 18 de julho de 2013. As informações colocam que "a indústria paulista encerrou o mês de junho com 4,5 mil empregos a menos em comparação com o quadro de funcionários verificado em maio" (FIESP, 2013, p. 01). Neste cenário, de repetidas crises econômicas nos últimos anos, constante fechamento de postos formais de trabalho, as medidas protecionistas e compensatórias disparas pelos documentos, mais do que objetivarem lidar com o imprevisto (risco) que acabam, em toda certeza possível e conflituosa acontecendo não deixando espaço para qualquer aventura que poderia, exemplificando possibilidades, estar na promoção e alteração do foco no emprego para contemplar formas distintas de atividades laborais como a ocupação, as iniciativas solidárias, dentre outros.

Entretanto, não ignoramos os limites do conceito de risco-aventura, que são de dois fundamentos: No primeiro deles, destacamos a necessária reflexão quanto aos limites entre aventura e imprudência, ou entre liberdade e abandono. A utilização apressada do risco-aventura pode esconder um discurso culpabilizante dos sujeitos que no exercício do "tudo pode", seriam colocados em um jogo do "nada ocorre"; No segundo, como discutido por Caponi (2001; 2004; 2009) quando aborda a presença da categoria risco na saúde pública (que é um significativo ponto de investimento de seus estudos). Ela chama a atenção para como, mesmo o risco positivado, ainda traria inscrições em dimensões socialmente aceitas. A autora ainda exercita a lembrança ao mostrar como que o risco na saúde é evitado pelo cálculo e gestão a partir da identificação dos efeitos perigosos e estratégias preventivistas. Nessa perspectiva, diferenciar o risco socialmente aceito dos inaceitáveis (como o uso de alguns medicamentos, por exemplo) seria crucial. Este segundo fundamento desdobrase no conflito entre quais riscos devem ser evitados e quais são inerentes à existência humana. Com esses apontamentos, Caponi caminha rumo a uma interessante sugestão de redefinição do que seria saúde, isso a partir das proposições de Georges Canguilhem, como problematizaremos.

A DUDH e a Constituição são marcos, porém seria exagerado atribuir a elas o poder de mudar as desigualdades sociais no Brasil ou no mundo. Mais do que alterações da realidade, elas buscam ordenar e administrar a vida, sendo sistemas táticos de governo da vida e do corpo social. Governar como sinônimo de gestão dos riscos.

Ao mapearmos e discutirmos a presença do Trabalho em cartas jurídicas, recorremos à Foucault (2003) quando este destaca que contrariamente a ideia do direito e das leis como regras coletivas e abstratas que circunscrevem as relações sociais, é necessária a clareza de que os princípios jurídicos estão referidos aos princípios de racionalidade. Estes são regimes de verdades que emanam práticas econômicas, culturais, sociais e políticas em um contexto. As legislações e documentos produzidos pelo Estado não podem ser descolados da história que os constituem e os atravessam.

Mapeamos até aqui a presença do trabalho como direito social na DUDH e na Constituição Brasileira, e sinalizamos como por esses mesmos escritos, trabalho e saúde começam a serem articulados de forma cada vez mais intensa: ambos os documentos 
colocam como que uma atividade laboral e o retorno que dela podemos obter, é importante para o indivíduo tanto a partir de aspectos objetivos (como a obtenção da remuneração), quanto subjetivos (como a sustentação da dignidade e o reconhecimento social), bem como esses aspectos contribuem de forma significativa para o estabelecimento e manutenção de nossa humanidade, de forma que torna-se inegável a centralidade do Trabalho para nossos laços sociais e nossa arquitetura psíquica e vida mental. Enfim, para o conjunto de nossa vida.

$\mathrm{O}$ que o Trabalho coloca em xeque, e os documentos capturam, é a complexidade da vida, do equilíbrio saúde-doença, bem como a implicação que aspectos internos e externos ao trabalho impõem ao sujeito que trabalha e a própria atividade de trabalho.

O Trabalho direito social, como constituído nos documentos até aqui analisados, indica o reconhecimento jurídico, em âmbito internacional e nacional, das dimensões e complexidades do trabalhar. É a partir dessa constatação que de direito social à emergência como dispositivo de atenção e cuidado, que o Trabalho adentrará a legislação de saúde.

\section{A Legislação de Saúde: trabalho como dispositivo de saúde}

A Constituição Brasileira promulgada em 1988, é um documento representativo de um amplo processo de abertura do país. No âmbito da saúde, a criação e posterior implantação do SUS garantiu legalmente uma democratização da assistência e do cuidado em saúde:

O Sistema Único de Saúde foi criado (...) com a finalidade de alterar a situação de desigualdade na assistência à Saúde da população, tornando obrigatório o atendimento público a qualquer cidadão (...) O SUS tem como meta tornar-se um importante mecanismo de promoção da equidade no atendimento das necessidades de saúde da população, ofertando serviços com qualidade adequados às necessidades, independente do poder aquisitivo do cidadão. O SUS se propõe a promover a saúde, priorizando as ações preventivas, democratizando as informações relevantes para que a população conheça seus direitos e os riscos à sua saúde (Ministério da Saúde, 2013, p. 01).

Parte crucial dessa democratização no acesso à saúde foi o fim do critério, até então vigente, de que somente trabalhadores contratados pelo regime da Consolidação das Leis do Trabalho (CLT) e contribuintes da Previdência Social poderiam dispor da assistência, o que promoveu o enfraquecimento de uma cidadania regulada (Santos, 1979) a que a população brasileira era submetida. O fim do acesso seletivo da população à saúde compôs uma ampliação que foi do próprio conceito de saúde. Discussões e mobilizações percorreram o Brasil e outros países da América Latina nas décadas de 70 e 80, impulsionadas por questionamentos e insatisfações da coletividade quanto às condições sociais, econômicas e políticas em que a vida desenrolava-se. Quanto à saúde, os sistemas até então vigentes mostravam-se em descompasso com as necessidades e os anseios da população.

No Brasil, as mobilizações não eram centradas apenas na saúde, em seu modelo de assistência ou sua estrutura institucional. A movimentação pela saúde era uma peça que em uma batalha mais extensa por outros modos de ser e viver, mobilizavam e aproximavam segmentos e grupos sociais diversos. A saúde compreendida como dimensão ampliada da vida começa a evidenciar-se.

Em 1986, a VIII Conferência Nacional de Saúde (CNS) formulou o que também ficou conhecido como, justamente, "conceito ampliado" de saúde. Defendia-se o direito à saúde como noção básica para a formulação de políticas públicas e chamavase a atenção para as condições de existência (vida biológica, social e cultural) e para como o estado de saúde seria revelado por essas formas de vida (Brasil, 1986)

Em sentido amplo, a saúde é a resultante das condições de alimentação, habitação, educação, renda, meio ambiente, trabalho, transporte, emprego, lazer, liberdade, acesso e posse da terra e acesso aos serviços de saúde. Sendo assim, é principalmente resultado das formas de organização social, de produção, as quais podem gerar grandes desigualdades nos níveis de vida (Brasil, 1986, p. 4).

O Relatório da Conferência de 1986 (Brasil, 1986) foi sustentação para o aprofundamento das discussões sobre a reestruturação da saúde no país, e poucos anos depois a Constituição e o SUS foram aprovados. A saúde, como contemplada no texto constitucional de 1988, significou uma conquista social fruto do amadurecimento do debate político que vinha ocorrendo, ganhando maior solidez em 1990 com a aprovação da Lei 8.080 (Brasil, 1990) em que, em oposição à concepção biomédica, as dimensões econômica, social e política na produção da saúde e da doença nas coletividades foram resgatadas.

$\mathrm{O}$ direito à saúde significa a garantia, pelo Estado, de condições dignas de vida e de acesso universal e igualitário às ações e serviços de promoção, proteção e recuperação da saúde, em todos os níveis, a todos os habitantes do território nacional, levando ao desenvolvimento pleno do ser humano em sua individualidade (Brasil, 1986, p. 382).

A partir da Constituição de 88 e do SUS, saúde e trabalho tornam-se, constitucional e institucionalmente, reconhecidos como direitos sociais coletivos garantidos mediante políticas públicas que compõem-se e definem-se mutuamente. Além disso, ambos passam também a serem legalmente vistos como componentes da dimensão social da cidadania:

A saúde tem como fatores determinantes e condicionantes, entre outros, a alimentação, a moradia, o saneamento básico, o meio ambiente, 
o trabalho, a renda, a educação, o transporte, o lazer e o acesso aos bens e serviços essenciais. (...) Dizem respeito também à saúde as ações que, (...) se destinam a garantir às pessoas e à coletividade condições de bem-estar físico, mental e social (Brasil, 1990, p. 01).

A concepção de saúde como a Constituição traz, tem o mérito de propor-se a olhar a vida de forma mais amplificada do que o biologismo individual anteriormente privilegiado. No entanto, críticos (Caponi, 1997, dentre outros) fazem ressalvas apontando que não há uma discussão quanto ao conceito, mas uma apresentação deste. Essa ausência estimularia há uma única dimensão a ser considerada, a socioeconômica, esvaziando os aspectos biológicos e psíquicos. O mesmo teria ocorrido, em comparativo, ao conceito de saúde proposto pela OMS (Organização Mundial de Saúde) $)^{2}$, em que a amplitude da atuação poderia contribuir para uma medicalização do social e do sujeito benemérito que nele transita (Segre \& Ferraz, 1997). Tais perspectivas encontrariam fortes ecos nas ações de promoção da saúde, como demonstraram alguns estudos (Lefevre \& Lefevre, 2004, dentre outros).

Caponi (1997; 2001), produzindo uma interlocução entre a definição ampliada de saúde e a obra de Georges Canguilhem, faz o exercício reflexivo e propositivo de um outro conceito de saúde, que privilegiaria as contribuições desse autor.

Foi com a tese de doutorado em Medicina que constituiria sua mais conhecida obra, que Canguilhem (2011) problematizou a racionalidade das práticas clínicas e dos conceitos que as permeariam. Ele lançou a discussão sobre o que seria a doença e em que ela consistiria, questão crucial em seus estudos. Canguilhem (2011) construiu uma vasta reflexão sobre a vida e a saúde a partir de sua positividade, deixando de defini-las por suas oposições. Há a primazia da vida em seus estudos com a denúncia de que as imposições normativas (mesmo as momentâneas), que enquadrariam os sujeitos nas condições consideradas saudáveis e adequadas de vida, deveriam ser abandonadas. A vida, para o autor, não deveria ser sujeitada as normas já que elas seriam produtos do próprio movimento da vida. Atentar-se a isso é o desafio que Canguilhem lança: saúde seria compreendida, então como "margem de tolerância (ou de segurança), que cada um possui para enfrentar e superar as infidelidades do meio" (Caponi, 1997, p. 291) que é imposto aos sujeitos pelas suas normativas. Tolerar, enfrentar e superar, não de forma adaptativa, mas em um equilíbrio dinâmico, seria a aventura da construção da saúde. Assim como poder desobedecer,

2- Lembrando: "A saúde é um estado de completo bem-estar físico, mental e social, e não consiste apenas na ausência de doença ou de enfermidade. Gozar do melhor estado de saúde que é possível atingir constitui um dos direitos fundamentais de todo o ser humano" (OMS, 2013, 01). poder adoecer e sair do estado patológico em formas singulares.

Nota-se como que a concepção de saúde, proposta por Canguilhem, inclui as vivências do sofrimento e da doença. Como categorias de um mesmo conjunto elas compõem-se e não anulam-se. Para o autor, saúde abandona a ideia do não adoecimento, tornando-se a capacidade de criar novas normas, novas formas de viver singularmente frente aos imprevistos e variações inerentes às dores cotidianas da vida, inclusive criando novas formas de adoecer. Assim, ninguém mais do que o próprio sujeito para saber e falar sobre suas vivencias de saúde e de doença, sem polarizá-las como valor e contravalor existencial.

Quando um indivíduo começa a se sentir doente, a se dizer doente, a se comportar como doente, ele passou para um outro universo, ele tornou-se um outro homem. A relatividade do normal não deve de nenhuma maneira ser para o médico um estímulo a anular na confusão a distinção do normal e do patológico (...). Considerado em seu todo, um organismo é 'outro' na doença e não o mesmo em dimensões reduzidas (Canguilhem, 2011, p. 165).

Experimentar e criar diante à vida é também ter condições para isso. Sem naturalizar mazelas ou condições de vida desfavoráveis, Caponi (1997) aponta como que integrar o conceito de saúde como margem de segurança pode trazer uma demasiada valorização individualista para o fenômeno saúdedoença, ignorando-se os determinantes sociais.

"Poderia-se argumentar que ao falar da necessidade de integrar essas infidelidades do meio como um elemento indispensável para tematizar a saúde, se corre o risco de legitimá-las em lugar de combatê-las" (Caponi, 1997, p. 304).

Mais uma vez a questão da medicalização do social vem à tona. Patologizar e medicar formas de ser, e de ser em determinados contextos, tosariam as populações em suas estratégias e dos conflitos (ou dos vir a ser) de enfrentamento autônomo das infidelidades do meio. Haveria ainda os riscos do uso de ações terapêuticas no meio social, possibilidade francamente higienista. Nesse viés, a disposição proposta é a extensão do conceito de Canguilhem para o âmbito social: saúde como tolerância e criação diante das infidelidades do meio (Caponi, 1997).

Ao trazer a perspectiva canguilhemiana para social não há como excluir o trabalho desse arranjo. O trabalho envolve relações entre o meio, os pares e os coletivos, com quem vive-se e trabalha-se. $\mathrm{Na}$ experiência-trabalho os desafios e os embates são inevitáveis, mas são também oportunidades para que sujeitos constituam-se, e apropriando-se do visto/ vivido desenvolvam diversas e novas formas de ser, viver e trabalhar em diferentes épocas e organizações sociais. Assim, o trabalho é fim (como o da produção de uma obra), mas também é o meio (como da produção de experimentações).

Com o empréstimo das problematizações de 
Canguilhem em composição com os dizeres de outros autores, estudiosos do trabalho (Dejours, 1993; 2004; 2003; Lancman \& Uchida, 2013), não há como pensar a atividade laboral como apenas uma questão de adaptação às exigências e normas que o trabalho nos impõe. Sendo que nessa perspectiva simplista, o trabalho torna-se uma dimensão limitada em que abandona-se toda a composição subjetiva de sua vivência. É a normativa colocada pelo trabalho, mas é também todo o espaço de possibilidade de reinvenção das atividades laborais (normas várias, colocadas/ criadas por sujeitos diversos: agentes internos e externos as tarefas) que o trabalho destaca-se como componente outro na objetividade do trabalhar. É o confronto paradoxal da experiência-trabalho (entre o que devo fazer e o que posso criar, e mesmo para alguns, o que devo criar e o que possa fazer) que o revela único como componente na batalha do processo pela saúde, bem como para outros processos.

A possibilidade criadora que o trabalho coloca em voga é de grande relevância para a conquista da saúde: é a apropriação, reapropriação e reinvenção no processo de trabalhar que tira o sujeito de uma relação de passividade, o afastando do adoecimento.

Dejours (1993) nos lembra de que na relação saúdetrabalho (enquanto componentes de vida, ou enquanto dimensões relacionadas em cada exclusividade de objetivo e momento), mais do que a existência ou não do trabalho, é necessária à indagação: qual trabalho?:

(...) do ponto de vista da saúde, a questão não é a de trabalhar ou não trabalhar - o que configuraria um falso problema. As questões são outras: trabalhar para que, para quem, com quem, por quanto tempo, em que horários, com que ferramentas, em que condições e formas de organização, estabelecendose os tipos de relação e de encontros. A questão que se apresenta é esta: que tipo de trabalho? (Brito \& Athayde, 2011. p. 26, grifo dos autores).

A partir da clareza de que trabalho e saúde imbrincam-se em uma interdisciplinaridade, e que suas efetivações como direitos e como dispositivos de cuidado são questões de cidadania em sua integralidade e positividade, afirmamos que este artigo destaca-se ao propor-se a cartografar esse processo e a denunciar como que as concepções trabalho-saúde (como direitos e como dispositivos relacionados) são limitadamente apresentados e aprofundados nas políticas públicas do Brasil, ou por ele assumidas. É clara a importância do trabalho como direito social, e acompanhamos como que essa compreensão fundamenta o trabalho como dispositivo de saúde. Mas, enquanto tarefa necessária, apontamos também como que nesse processo o questionamento (a partir da proposta de Dejours e Brito \& Athayde) e as indagações de "que tipo de trabalho?" estão ausentes dos documentos mestres jurídicos.

O ponto que aqui destacamos é de que não basta reconhecer o trabalho como direito social, indicar seu protagonismo como estratégia de saúde, ou direcionar esforços políticos (como veremos em programas e eixos de ações públicas) sem dimensionar ou delinear esse "que tipo de trabalho?" enquanto condições de vida para uma construção mais livre, criativa e positiva do próprio trabalho, e por consequência, da saúde em suas referências da vida e das formas de ação sobre ela.

Saúde não é silêncio, mas movimento, muitas vezes ruidoso. O trabalho é componente nos movimentos e nos barulhos. Enquadrá-los ou retirarse das discussões que envolvam seus laços são formas de enquadramento e controle existencial. Desta forma, as Políticas Públicas de saúde, trabalho e as intersetoriais, devem ser o compromisso da ampliação da vida sem, claro, excluir os indivíduos, proprietários das vidas em questão.

O SUS, sem dúvida, foi e é uma oportunidade do exercício desse compromisso ao ser criado com a proposta de ser um sistema de acesso integral, universal e igualitário de toda população brasileira, exigindo uma reorientação do sistema de saúde até então vigente, que trazia o foco na medicina curativa. Novas políticas de saúde foram construídas, entre as quais as de saúde mental. Ao longo dos anos de existência do SUS, normatizações, decretos, portarias e publicações diversas de programas, ações e estratégias que atualizaram, alteraram ou revisaram aspectos organizacionais e operacionais do sistema foram publicados na tentativa de acompanhar a afluência da vida. Novas práticas de saúde foram contempladas marcadas pela indissociabilidade entre ações clínicas e ações coletivas de saúde (promoção, prevenção e cuidado). Diversos esforços discursivos e práticos, que em comum, percorrem os objetivos de colocar em sintonia os princípios preconizados pelo SUS, bem como sua consolidação. O SUS é resultado de um processo longo e complexo de correlação de forças que envolveram aspectos históricos, políticos e epistemológico, em que a saúde em sua intersetorialidade e integralidade, como princípios constitucionalmente garantidos, tornaramse protagonistas. Intersetorialidade e integralidade compreendidos como ações orientadas em distintos eixos que articulam saberes em uma rede integral de atenção em saúde, evitando a fragmentação do cuidado em saúde, e do olhar sobre o próprio sujeito e sua vida. Neste contexto, a Saúde Mental comporá e aprofundará o enlace entre esses campos, exigindo escritos específicos que dimensionem e norteiem essas relações, discussão que não realizaremos aqui.

Diante dessa exposição, acreditamos que a análise da articulação Trabalho-Saúde como aqui realizada, é um ato político. Os documentos oficiais (como os materiais aqui analisados) são espaços de emergência dos saberes e das verdades produzidas pelo Estado. Colocar perguntas a eles é impedir que sejam entendidos como dados, e pacífica e obedientemente acoplados às formas de viver. $\mathrm{O}$ questionamento abre 
a possibilidade para efetuar a crítica como resistência, movendo o jogo dos dados para que outras histórias, outros escritos, e outros saberes sejam fomentados.

\section{Referências}

Brasil. (1986). VIII Conferência Nacional de Saúde: relatório final. Brasília: Ministério da Saúde. Acessado de http://conselho. saude.gov.br/biblioteca/Relatorios/relatorio8.pdf

Brasil. (1988). Constituição da República Federativa do Brasil. Poder Legislativo, Brasília.

Brasil. (1990, Setembro 20). Lei n. ${ }^{\circ} 8.080$. Diário Oficial da União, Brasília.

Brasil; Ministério da Saúde (2009). Sistema de planejamento do SUS (PlanejaSus): uma construção coletiva - trajetória e orientações de operacionalização. Ministério da Saúde/ Organização Pan-Americana da Saúde. Brasília: Ministério da Saúde. Acessado de http://bvsms.saude.gov.br/bvs/publicacoes/ planejaSUS_livro_1a6.pdf

Brito, J. Athayde, M. (2011). Saúde, cadê você, cadê você? In: Brito, J.; Neves, M.Y.; Athayde, M. (Orgs.). Caderno de textos: programa de formação em saúde, gênero e trabalho nas escolas (pp. 16-27). Rio de Janeiro: ENSP/FIOCRUZ.

Canguilhem, G. (2011). O normal e o patológico. ( $7^{\mathrm{a}}$ ed). Rio de Janeiro: Forense Universitária.

Caponi, S. (1997, Out.). Georges Canguilhem y el estatuto epistemológico del concepto de salud. Hist. cienc. saudeManguinhos, v. 4, n. 2. Acessado de http://www.scielo.br/scielo. php?script=sci_arttext\&pid=S0104-59701997000200006\&lng=en \&nrm=iso

Caponi, S. (2001, Nov./Dez.). La aceptabilidad del riesgo. Cad. Saúde Pública, v.17, n.6. v.1.

Caponi, S.N.C. (2004). Saúde pública, riscos privados. Salus,

Caponi, S. (2009). A saúde como abertura ao risco. In: Czeresnia, D.; Freitas, C.M. Promoção da saúde: conceitos, reflexões, tendências (pp. 55-77). Rio de Janeiro: Editora Fiocruz.

Declaração Universal dos Direitos Humanos (DUDH) (1948). Assembleia Geral da ONU. Acessado de http://unesdoc.unesco. org/images/0013/001394/1394 23por.pdf

Dejours, C. (1993, Mai/Jun.). Por um trabalho, fator de equilíbrio. RAE. São Paulo, 33(3): 98-104. Acessado de http:// www.scielo.br/pdf/rae/v33n3/a09v33n3.pdf

Dejours, C. (2003). A loucura do trabalho: estudo de psicopatologia do trabalho. ( $5^{\mathrm{a}}$ ed.). São Paulo: Cortez.

Dejours, C. (2004). Subjetividade, trabalho e ação. Revista Produção, v. 14, n. 3, p. 27-34

Deleuze, G. (2010). Post-scriptum sobre as sociedades de controle. In: Deleuze, G. Conversações: 1972-1992. (2a. ed.). Rio de janeiro: Editora 34.

Ewald, F. (1993). Foucault, a norma e o direito. Lisboa: Editora Vega.

Federação das Indústrias do Estado de São Paulo (FIESP) (2013, Jul.). Indústria fecha 4,5 mil vagas de trabalho em junho. Alice Assunção, Agência Indusnet Fiesp. Acessado de http://www. fiesp.com.br/noticias/industria-fecha-45-mil-vagas-de-trabalhoem-junho/

Fonseca, C.R.; Araújo, L.F.J.B. (2011). A influência da Declaração Universal dos Direitos Humanos no direito brasileiro. Revista Jus Navigandi. Acessado de http://jus.com.br /revista/ texto/21440/a-influencia-da-declaracao-universal-dos-direitoshumanos-no-direito-brasileiro

Foucault, M. (1986). Microfísica do Poder. (6a. ed.). Rio de Janeiro: Editora Graal.

Foucault, M. (2003). A vida dos homens infames. In: Motta, M. B. da (Org.) Estratégia, poder-saber. Coleção ditos e escritos, v. IV. São Paulo: Forense Universitária.

Lancman, S.; Uchida, S. (2013). Trabalho e subjetividade: o olhar da psicodinâmica do trabalho. Cad. psicol. soc. trab. Acessado de http://pepsic.bvsalud.org/ scielo.php?script=sci arttext\&pid=S1516-37172003000200006\&lng $=$ pt $\&$ nrm $=$ iso
Lefevre, F.; Lefevre, A. M. C. (2004). Promoção de saúde: a negação da negação. Rio de Janeiro: Editora Vieira e Lent.

Luz, M.T. (2001, Dez.). Risco, perigo e aventura na sociedade da (in) segurança: breve comentário. Cad. Saúde Pública, v. 17, n. 6. Acessado de http://www.scielo.br /scielo.php?script=sci arttext\&pid=S0102-311X2001000600003\&lng=e n \&nrm=isso

Ministério da Justiça (2013). Direitos do cidadão: Declaração Universal dos Direitos Humanos. Acessado de http://www.brasil. gov.br/sobre/cidadania/direitos-do-cidadao/declaracao-universaldos-direitos-humanos.

Ministério da Saúde (2013). Sistema Único de Saúde. Disponível em http://portal. saude.gov.br/portal/saude/visualizar_ texto.cfm?idtxt $=24627$.

Organização das Nações Unidas no Brasil (2013). A ONU e os direitos humanos. Acessado de http://www.onu.org.br/

Santiago, E.; Yasui, S. (2011). O trabalho como dispositivo de atenção em saúde mental: trajetória histórica e reflexões sobre sua atual utilização. Revista de Psicologia da UNESP, v. 10, n. 1, Acessado de http://www2.assis.unesp.br/revpsico/index.php/ revista/article/view/191/246

Santos, W.G. (1979). Cidadania e justiça: a política social na ordem brasileira. Rio de Janeiro: Editora Campus.

Segre, M.; Ferraz, F. C. (1997, Out.). O conceito de saúde. Rev. Saúde Pública, v. 31, n. 5. Acessado de http://www.scielo.br/scielo. php?script=sci arttext\&pid=S0034-89101997000600016\&lng=en $\&$ nrm $=$ iso

Conselho Nacional de Saúde; Ministério da Saúde (2010). Comissão organizadora da VI Conferência Nacional de Saúde Mental: Intersetorial. Relatório Final da IV Conferência Nacional de Saúde Mental: Intersetorial, 27 de junho a 1 de julho de 2010. Brasília: Conselho Nacional de Saúde/Ministério da Saúde. Acessado de http://conselho.saude.gov.br/biblioteca/Relatorios/ relatorio_final_IVcnsmi_cns.pdf

Spink, M.J.P.; Medrado, B.; Mello, R. P. (2002). Perigo, probabilidade e oportunidade: a linguagem dos riscos. Psicol. Reflex. Crit., v. 15, n. 1. Acessado de http:// www.scielo. $\quad$ br/scielo.php?script=sci_arttext\&pid=S010279722002000100017\&lng=em \&nrm=iso

Spink, M.J.P. (2010). Psicologia social e saúde: práticas, saberes e sentidos. (7a. ed.). Petrópolis: Vozes 


\section{Sobre os autores}

Eneida Santiago -UEL - Universidade Estadual de Londrina - Centro de Ciências Biológicas, Depart. de Psicologia Social e Institucional E-mail: ensantiagobr@yahoo.com.br

Silvio Yasui - Unesp/Assis - Universidade Estadual Paulista, Campus de Assis - Depart. de Psicologia Evolutiva, Social e Escolar 